\title{
DESENVOLVIMENTO DE UM MÉTODO EMPREGANDO QUITOSANA PARA REMOÇÃO DE ÍONS METÁLICOS DE ÁGUAS RESIDUÁRIAS
}

\author{
Bruno Campos Janegitz, Bruna Cláudia Lourenção, Karina Omuro Lupetti ${ }^{\#}$ e Orlando Fatibello-Filho* \\ Departamento de Química, Universidade Federal de São Carlos, CP 676, 13560-970 São Carlos - SP, Brasil
}

Recebido em 12/5/06; aceito em 28/9/06; publicado na web em 27/4/07

\begin{abstract}
DEVELOPMENT OF A METHOD EMPLOYING CHITOSAN TO REMOVE METALLIC IONS FROM WASTEWATER. In this work a method was developed for removing metallic ions from wastewaters by co-precipitation of $\mathrm{Cu}^{2+}, \mathrm{Pb}^{2+}, \mathrm{Cd}^{2+}, \mathrm{Cr}^{3+}$ and $\mathrm{Hg}^{2+}$ with chitosan and sodium hydroxide solution. Solutions of these metallic ions in the range from 0.55 to $2160 \mathrm{mg} \mathrm{L}^{-1}$ were added to chitosan dissolved in $0.05 \mathrm{~mol} \mathrm{~L}^{-1} \mathrm{HCl}$. For the co-precipitation of metal-chitosan-hydroxide a $0.17 \mathrm{~mol} \mathrm{~L}^{-1} \mathrm{NaOH}$ solution was added until $\mathrm{pH}$ 8.5-9.5. A parallel study was carried out applying a $0.17 \mathrm{~mol} \mathrm{~L}^{-1} \mathrm{NaOH}$ solution to precipitate those metallic ions. Also, a chitosan solid phase column was used for removing those metallic ions from wastewaters.
\end{abstract}

Keywords: chitosan; metallic ions; adsorption.

\section{INTRODUÇÃO}

A indústria química ${ }^{1}$ vem apresentando crescimento acentuado nos últimos anos. A questão ambiental que abrange os produtos gerados pelo setor químico vem sendo debatida no Brasil e no mundo nos últimos anos. Em vista da crescente exigência da sociedade, especialmente dos órgãos de proteção ao meio ambiente, como CETESB e CONAMA, vêm sendo desenvolvidos novos métodos ${ }^{2}$ para tratamento de efluentes contaminados por íons metálicos, tais como mercúrio, cádmio, cobre, crômio, chumbo, entre outros.

Esses íons metálicos ${ }^{3}$ são encontrados nos resíduos provenientes de algumas indústrias, os quais não são devidamente tratados sendo, então, despejados de forma inadequada nos rios e por não serem biodegradáveis, tendem a se acumular.

Os íons metálicos possuem uma alta toxicidade ao ser humano em concentrações inadequadas, podendo causar diversas doenças e distúrbios. A tolerância ambiental para estes íons é estabelecida pelo Conselho Nacional de Meio-Ambiente, CONAMA ${ }^{4}$.

$\mathrm{O}$ crômio ${ }^{5}$ é encontrado naturalmente em rochas, plantas, solo, poeiras e névoas vulcânicas. Os efeitos tóxicos em indivíduos expostos ocupacionalmente a elevadas concentrações de crômio, particularmente o crômio (VI), incluem ulcerações e perfuração do septo nasal, irritação do trato respiratório, possíveis efeitos cardiovasculares, gastrointestinais, hematológicos, hepáticos e renais, além do risco elevado de câncer pulmonar.

O cobre ${ }^{5}$ é amplamente distribuído na natureza, podendo ser encontrado na forma de sulfetos, arsenitos, cloretos e carbonatos. Quando em excesso, causa ao ser humano as seguintes reações adversas: deslocamento do metal de seus sítios de ligação resultando em alterações nas membranas, como despolarização, e dano dos receptores ou moléculas transportadoras. A intoxicação aguda por cobre causa erosão do epitélio gastrointestinal associado à necrose centrilobular do fígado e necrose tubular dos rins.

Altas concentrações de cádmio podem ser encontradas em rochas sedimentares e fosfatos marinhos. A toxicidade do cádmio

\# endereço atual: Instituto de Química de São Carlos, Universidade de São Paulo, CP 780, 13560-970 São Carlos - SP, Brasil

*e-mail: bello@dq.ufscar.br expressa-se em diversos órgãos e tecidos, entretanto, os órgãosalvo são rins e fígado. Nas situações de exposição crônica, a toxicidade se expressa nos rins a nível de túbulo proximal provocando dano celular, sendo também relacionada à redução de glicogênio hepático e ao aumento de glicemia.

$\mathrm{O}$ mercúrio ${ }^{5}$ é raramente encontrado como elemento livre na natureza. Encontra-se amplamente distribuído, porém em baixas concentrações, por toda a crosta terrestre. O mercúrio e seus compostos podem causar vários danos à saúde, tanto em situações de exposição aguda quanto crônica. Por sua afinidade, interfere com grupos sulfidrilas presentes em proteínas e sistemas enzimáticos em diferentes tecidos e órgãos. O rim é o órgão crítico na intoxicação aguda pelo íon mercúrio, ocorrendo extensa necrose de células epiteliais.

$\mathrm{O}$ chumbo ${ }^{5}$ é um elemento de ocorrência natural, encontrado com relativa abundância na crosta terrestre, quase sempre como sulfeto de chumbo (galena). Esse metal é distribuído entre órgãos como rins, fígado, dentre outros e, também, em ossos e dentes. Os ossos podem ser adversamente afetados pelo chumbo, mas também servem como os maiores reservatórios do elemento no organismo.

Para tratamento desses metais em água podem ser utilizados alguns procedimentos, dentre eles, precipitação com hidróxidos, remoção com resinas de troca iônica, argila, zeólitas naturais, cinzas industriais, carvão vegetal, quitina, quitosana, entre outros ${ }^{6-10}$.

Um método convencional de tratamento dos efluentes industriais consiste na precipitação dos íons metálicos. Essa precipitação pode estar associada, se necessário, a um pré-tratamento para liberar o íon metálico de agentes quelantes. Essas substâncias reagem com os metais dissolvidos formando complexos solúveis em soluções neutras ou ligeiramente alcalinas $(\mathrm{pH}>7)$.

A quitosana ${ }^{11,12}$ é obtida a partir da desacetilação da quitina por processos de hidrólise básica e composta pelas unidades 2-amino2-desoxi-D-glicopiranose e 2-acetamido-2-desoxi-D-glicopiranose, as quais são unidas por ligações glicosídicas do tipo $\beta(1 \rightarrow 4)$. Esse biopolímero apresenta importantes propriedades biológicas tais como baixa toxicidade, não causa alergia, pode ser empregado como anticoagulante, é biodegradável, biocompatível e possui propriedades antibacterianas.

Esse biopolímero ${ }^{11-14}$ é insolúvel em água, bases, álcool e acetona, sendo completamente solúvel em soluções de alguns ácidos or- 
gânicos, como por ex., ácido acético em $\mathrm{pH}<6$. Alguns ácidos inorgânicos diluídos, tais como ácido nítrico, clorídrico, perclórico ou fosfórico, podem ser utilizados para preparação de soluções de quitosana somente depois de prolongada agitação e aquecimento.

Por ser uma fonte de matéria-prima altamente renovável e economicamente viável, a quitosana atualmente está sendo utilizada em diversas áreas, como medicina ${ }^{15}$, agricultura ${ }^{16}$, biotecnologia ${ }^{17}$, indústria de $\operatorname{cosmé} \cos ^{18}$, produtos alimentícios ${ }^{19} \mathrm{e}$, como adsorvente na remoção de corantes $^{20} \mathrm{e}$ espécies metálicas ${ }^{21}$.

A quitosana além de abundante e de baixo custo é um ótimo adsorvente de metais pesados ${ }^{22}$, possui capacidade para formar complexos com íons de metais de transição devido à presença de amino-grupos presentes em sua estrutura, como mostra a Figura 1, sendo seu poder quelante para diversos cátions metálicos da ordem de 5 a 6 vezes acima da quitina ${ }^{11,23}$. Apresenta alta capacidade de adsorção, maior que $1 \mathrm{mmol}$ do cátion metálico/g de quitosana para a maioria dos íons metálicos. A capacidade de adsorção da quitosana varia de acordo com a cristalinidade, afinidade por água, porcentagem de desacetilação e quantidade de amino-grupos.

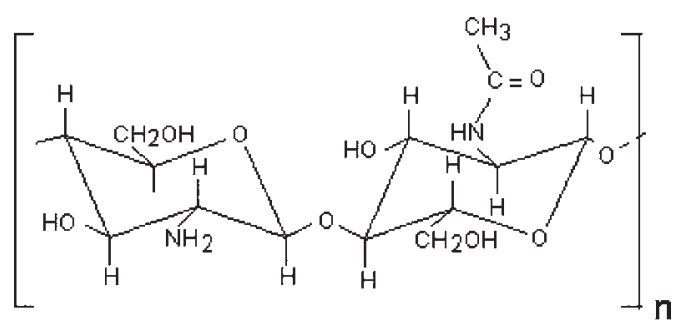

Figura 1. Estrutura da quitosana

Segundo Canella et al. ${ }^{24}$, as propriedades físicas e químicas da quitina e de seus derivados $\mathrm{N}$-desacetilados (quitosana) são muito diferentes. A quitosana comercial possui, geralmente, grau médio de desacetilação (GD) variando de 70 a $95 \%$, com massa molar na faixa de $10^{4}-10^{6} \mathrm{~g} \mathrm{~mol}^{-1}$. Como muitas das propriedades destes polissacarídeos estão intimamente relacionadas a estes dois parâmetros, torna-se imprescindível a determinação dos mesmos. Deste modo, o conhecimento preciso do teor de grupos N-desacetilados (G.D.) e, conseqüentemente, de grupos $\mathrm{NH}_{2}$, é importante, de maneira a caracterizar qualquer processo de desacetilação da quitina, assim como qualquer outra modificação química ${ }^{25}$. É necessário observar a influência das condições reacionais, tais como temperatura, concentração da base e número de etapas de reação na obtenção de quitosana de baixo grau de acetilação.

A quitosana tem sido empregada como agente para imobilização de uma variedade de substratos. Zwirtes e Vieira ${ }^{26}$ estudaram a construção e aplicação de biossensores utilizando diferentes procedimentos de imobilização da peroxidase de vegetal em matriz de quitosana. Ngah et al. ${ }^{27}$ estudaram a adsorção de cobre (II) em solução aquosa usando quitosana modificada.

Silva et al. ${ }^{28}$ apresentaram as aplicações farmacêuticas dos derivados hidrossolúveis da quitosana e seus avanços.

Segundo Klug et al. ${ }^{29}$, a introdução de certos grupos funcionais na matriz polimérica da quitosana poderá propiciar maior interação com um grande número de íons metálicos e, conseqüentemente, poderá ser empregada em processos de pré-concentração de íons.

$\mathrm{O}$ desenvolvimento ${ }^{30}$ de novos métodos para remoção de íons metálicos tem sido um desafio para o mercado tecnológico, pois o alto custo e, muitas vezes, as limitadas condições de trabalho dificultam o tratamento. Com alta massa molar e grande repetição dos grupos funcionais, a quitosana pode ser utilizada juntamente com materiais de menor custo para obtenção de alta eficiência nesse processo. Neste trabalho é proposto um método de co-precipitação de cátions metálicos com quitosana em meio básico.

\section{PARTE EXPERIMENTAL}

\section{Materiais e equipamentos}

Para a determinação do grau médio de desacetilação da quitosana, foi utilizado condutivímetro Micronal, mod. B330 com uma célula condutimétrica Digimed DMC-010. Para comparação dos resultados obtidos no estudo de caracterização da quitosana, utilizou-se a técnica de ressonância magnética nuclear de prótons (RMN-H) com o auxílio de espectrômetro de ressonância magnética nuclear Bruker, modelo DRX 400, de 9.4 Tesla, 400,13 MHz para freqüência do hidrogênio, sendo utilizada sonda de $5 \mathrm{~mm}$, de detecção inversa com gradiente de campo na direção do eixo $\mathrm{z}$.

Para monitoramento da eficiência de remoção dos íons metálicos das soluções de trabalho foi empregado espectrômetro de absorção atômica Varian, modelo Gemini. Para o monitoramento da eficiência de remoção dos íons mercúrio utilizando coluna empacotada com quitosana, empregou-se um ICP-OES Varian simultâneo com leitura axial e para monitoramento dos íons mercúrio das soluções padrão utilizou-se espectrofotômetro de absorção molecular HP 8452 A na região UV-visível.

\section{Estudos da dissolução da quitosana}

Diferentes soluções de quitosanas foram preparadas nas concentrações de 0,$100 ; 0,200 ; 0,500$ e 0,800 $\mathrm{g}$ em volumes variados (10-50 mL) de ácido clorídrico, sulfúrico e acético nas concentrações de 0,$05 ; 0,27 ; 0,55 ; 0,82$ e $1,09 \mathrm{~mol} \mathrm{~L}^{-1}$. Esses ácidos, nas diferentes concentrações, foram adicionados às massas de quitosana e a solução agitada por $3 \mathrm{~h}$.

\section{Caracterização da quitosana}

Quitosanas de diversas procedências como Sigma, Aldrich, Polymar e Purifarma foram caracterizadas, segundo o grau médio de desacetilação utilizando-se os métodos de RMN ${ }^{1} \mathrm{H}$ e titulação condutométrica ${ }^{31}$.

Os espectros de RMN ${ }^{1} \mathrm{H}$ foram obtidos a partir do procedimento descrito por Signini e Campana-Filho ${ }^{32}$. Aproximadamente $10 \mathrm{mg}$ de cada amostra de quitosana foram solubilizadas em $1 \mathrm{~mL}$ de solução $\mathrm{HCl} / \mathrm{D}_{2} \mathrm{O} 1 \%$ (v/v), durante $24 \mathrm{~h}$, formando uma solução viscosa. Uma alíquota de cada solução foi colocada em tubo de $5 \mathrm{~mm}$ de diâmetro para análise a $60{ }^{\circ} \mathrm{C}$. Como referência externa foi utilizado o ácido 3- (trimetilsilil)-1- propano sulfônico- d4 (TSPA da Aldrich).

Em cada titulação condutométrica foram utilizadas massas acuradamente medidas de $200 \mathrm{mg}$ de quitosana, que foram agitadas juntamente com $40 \mathrm{~mL}$ de solução de $\mathrm{HCl} 0,05 \mathrm{~mol} \mathrm{~L}^{-1}$ à temperatura de $25,0 \pm 0,1{ }^{\circ} \mathrm{C}$ e, em seguida, tituladas com solução de $\mathrm{NaOH} 0,17 \mathrm{~mol} \mathrm{~L}^{-1}$.

\section{Tratamento das soluções contendo os íons metálicos}

Após a caracterização das diferentes amostras de quitosana empregando-se os métodos descritos, foram realizados estudos para remoção dos íons metálicos $\left(\mathrm{Cu}^{2+}, \mathrm{Cr}^{3+}, \mathrm{Pb}^{2+}, \mathrm{Cd}^{2+}\right.$ e $\left.\mathrm{Hg}^{2+}\right)$ de diferentes soluções, utilizando-se a quitosana de maior grau médio de desacetilação.

Alíquotas de $3 \mathrm{~mL}$ das soluções de cátions metálicos no intervalo de concentrações de $5,0 \times 10^{-5}$ a $0,10 \mathrm{~mol} \mathrm{~L}^{-1}$ foram adicionadas separadamente nas soluçõs de quitosana dissolvida em meio 
ácido $^{32}$. Para a co-precipitação desse biopolímero com a espécie metálica, foram adicionados volumes crescentes de solução de $\mathrm{NaOH} 0,17 \mathrm{~mol} \mathrm{~L}^{-1}$ com auxílio de uma bureta, mantendo-se a solução sob agitação constante. Esse procedimento foi proposto pelo nosso grupo de pesquisa e tem levado a maiores rendimentos de remoção de diversos íons metálicos de águas residuárias ${ }^{33,34}$.

Após um período mínimo de $30 \mathrm{~min}$, necessário para a total decantação do precipitado, este foi filtrado e a concentração do íon metálico foi determinada por espectrofotometria de absorção atômica. No caso do $\mathrm{Hg}^{2+}$, a concentração desse cátion metálico foi determinada por espectrofotometria seguindo o procedimento proposto por Park e Choi ${ }^{35}$. Alíquotas do filtrado variando de 1 a $7 \mathrm{~mL}$ foram transferidas para balões volumétricos de $10 \mathrm{~mL}$. Em segui$\mathrm{da}$, foram adicionados $0,5 \mathrm{~mL}$ de iodeto de potássio, $0,7 \mathrm{~mL}$ de cloreto benzalcônio, sendo o volume completado com tampão bórax $(\mathrm{pH}=10)$. Após repouso de $20 \mathrm{~min}$, determinaram-se as absorbâncias das soluções em comprimento de onda de $280 \mathrm{~nm}$. Construiu-se uma curva analítica, que foi linear entre $1,4 \times 10^{-2}$ e $8,1 \mathrm{mg} \mathrm{L}^{-1}$.

Um experimento controle foi realizado adicionando-se diretamente solução de hidróxido de sódio na solução do cátion metálico (sem a quitosana).

Um método comparativo foi realizado utilizando colunas de vidro de $20 \mathrm{~mm}$ de diâmetro e $200 \mathrm{~mm}$ de comprimento contendo empacotados 2,5 g da quitosana Aldrich na forma sólida. Após adição daquela massa de quitosana em cada coluna de vidro, a coluna de quitosana foi compactada com o auxílio de bastão de vidro, sendo as partículas do polímero intumescidas com água destilada por 4-5 h.

Foram adicionadas alíquotas das soluções de $\mathrm{Pb}^{2+}, \mathrm{Cu}^{2+}, \mathrm{Cr}^{3+}$, $\mathrm{Hg}^{2+}$ e $\mathrm{Cd}^{2+}$, em determinadas concentrações de cada espécie metálica. Essas mesmas alíquotas foram coletadas na saída das colunas para determinação das concentrações dos íons por espectrofotometria de absorção atômica $\left(\mathrm{Pb}^{2+}, \mathrm{Cu}^{2+}, \mathrm{Cd}^{2+} \mathrm{e} \mathrm{Cr}^{3+}\right)$. No caso dos íons $\mathrm{Hg}^{2+}$ utilizou-se espectrometria de emissão óptica com plasma acoplado indutivamente (ICPOES).

\section{RESULTADOS E DISCUSSÃO}

\section{Avaliação da solubilidade da quitosana em meio ácido}

A solubilização da quitosana em diferentes ácidos, como acético, sulfúrico e clorídrico em diferentes concentrações, 0,$05 ; 0,27 ; 0,55$; 0,82 e 1,09 mol L-1 foi inicialmente investigada. Dos ácidos empregados para solubilização da quitosana, apenas o ácido clorídrico, nas concentrações variando de 2,5 a $7,5 \mathrm{~g} \mathrm{~L}^{-1}$ ( $\mathrm{g}$ de quitosana por $\mathrm{mL}$ de $\mathrm{HCl} 0,05 \mathrm{~mol} \mathrm{~L}^{-1}$ ), solubilizou totalmente a quitosana. Com o aumento da concentração do ácido clorídrico para $0,27 \mathrm{~mol} \mathrm{~L}^{-1}$, verificou-se uma diminuição da solubilidade da quitosana onde foi possível obter uma solução de no máximo $2,5 \mathrm{~g}$ de quitosana $\mathrm{L}^{-1} \mathrm{de}$ ácido clorídrico $0,27 \mathrm{~mol} \mathrm{~L}^{-1}$. Isso ocorre devido ao grande aumento da força iônica acompanhada pelo decréscimo do pH. Esses resultados estão em boa concordância com aqueles encontrados por Dockal et al. ${ }^{31}$. Outro fator que influencia a solubilidade da quitosana é o tipo de preparação empregada, onde as desacetilações homogêneas $(\mathrm{GD}=55-50 \%)$ levam a quitosanas solúveis em água e desacetilações heterogêneas, com o mesmo GD, levam a quitosanas insolúveis em água e ácido diluído ${ }^{36}$.

\section{Caracterização das quitosanas de diferentes procedências}

Após estabelecer a solubilidade da quitosana em meio ácido verificou-se o grau médio de desacetilação da quitosana de diferentes procedências (Purifarma, Polymar, Sigma e Aldrich).

O grau médio de desacetilação é definido como o número de grupos amino em relação aos grupos amida da cadeia polimérica. A determinação deste parâmetro implica na propriedade da quitosana em adsorver maior ou menor concentração de íons metálicos (o grupo amino disponível pode complexar alguns íons metálicos). Existem diversas metodologias empregadas para se determinar o grau médio de desacetilação, como $\mathrm{RMN}^{37}$, cromatografia ${ }^{38}$, infra-vermelho ${ }^{39,40}$, entre outros. Neste trabalho, o grau médio de desacetilação foi determinado por titulação condutométrica e por RMN ${ }^{1} \mathrm{H}^{31}$.

\section{Condutometria}

O grau médio de desacetilação foi determinado segundo Dockal et al. ${ }^{31}$. A Figura 2 apresenta as curvas condutométricas obtidas na titulação de quitosanas procedentes da Purifarma, Polymar, Sigma e Aldrich, respectivamente. De acordo com a Figura 2, o primeiro ramo linear da curva obtida corresponde à neutralização do $\mathrm{HCl}$ em excesso, o segundo à neutralização do grupo amino presente na quitosana e o terceiro corresponde aos íons $\mathrm{OH}^{-}$em excesso presentes na solução.

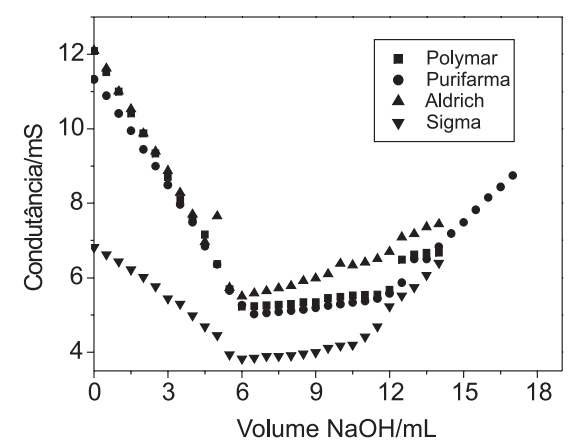

Figura 2. Curvas condutométricas obtidas na titulação das quitosanas com solução de $\mathrm{NaOH} \mathrm{0,17} \mathrm{mol} \mathrm{L}^{-1}$

O número de grupos amino em relação aos grupos amida da cadeia polimérica foi calculado empregando-se a Equação 1

$\% \mathrm{GD}=\frac{16,1[\text { base }](\mathrm{V} 2-\mathrm{V} 1)}{\mathrm{m}}$

onde: 16,1 é a fração molar de quitosana; [base] é a concentração de $\mathrm{NaOH}$ consumido, (V2-V1) é o volume de $\mathrm{NaOH}$ do segundo e primeiro pontos de equivalência e, $\mathrm{m}$ é a massa de quitosana utilizada na determinação.

Empregando-se a Equação 1 para o grau médio de desacetilação em percentagem, GD \%, proposta na literatura ${ }^{31}$, foram obtidos os graus médios de desacetilação das quitosanas como mostrado na Tabela 1.

\section{Ressonância magnética nuclear de prótons $\mathbf{R M N}{ }^{1} \mathrm{H}$}

Como técnica comparativa, determinou-se o grau médio de acetilação da quitosana por espectroscopia de RMN ${ }^{1} \mathrm{H}$, sendo en-

Tabela 1. Grau médio de desacetilação (GD) das quitosanas de diferentes procedências, utilizando as técnicas de condutometria e de $\mathrm{RMN}{ }^{1} \mathrm{H}$

\begin{tabular}{lcc}
\hline Procedência da quitosana & GD $1 *(\%)$ & GD $2 * *(\%)$ \\
\hline Purifarma & 71,9 & 87,5 \\
Polymar & 79,7 & 88,8 \\
Sigma & 84,3 & 87,7 \\
Aldrich & 85,8 & 87,3 \\
\hline
\end{tabular}

* condutometria; ** $\mathrm{RMN}{ }^{1} \mathrm{H}$ 
tão calculado o grau médio de desacetilação. Essa técnica mostrou ser eficiente na quantificação do grau médio de acetilação desde que a análise fosse realizada em meio ácido e a $60{ }^{\circ} \mathrm{C}$. Determinações a $70{ }^{\circ} \mathrm{C}$, como indicado na literatura ${ }^{32}$, levaram a um aumento da instabilidade do sistema. Mesmo trabalhando-se a $60{ }^{\circ} \mathrm{C}$, foi necessário que a varredura do espectro e a aquisição de dados fossem realizadas prontamente, de modo a minimizar problemas causados pela hidrólise ácida da quitosana. A Equação 2 foi utilizada para calcular o grau médio de acetilação:

$\% \mathrm{GD}=\left(\frac{\mathrm{A}\left(\mathrm{CH}_{3}\right)}{3 \mathrm{~A}\left(\mathrm{H}_{2}\right)}\right) \times 100$

onde $\mathrm{A}\left(\mathrm{CH}_{3}\right)$ representa os núcleos de hidrogênio metilados do grupo acetamido e $\mathrm{A}\left(\mathrm{H}_{2}\right)$ são os núcleos de hidrogênio na posição 2 do anel glicosamino.

$\% \mathrm{GD}=100-\% \mathrm{GA}$

A escolha da relação de áreas da Equação 2 deve-se ao fato de que as áreas dos grupos metila encontradas na região de 2 ppm relativas aos núcleos do grupo acetamido e ao núcleo na posição 2 do anel glicosamino encontrados na região de 3,2 ppm estão livres das influências de pico de HOD $(\delta=3,8$ ppm). A Equação 3 , então, determina o grau médio de desacetilação das quitosanas. A Figura 3 apresenta o espectro de RMN obtido para a quitosana procedente da Aldrich. O grau médio de desacetilação obtido para cada quitosana empregando-se a técnica condutométrica e ressonância magnética nuclear de hidrogênio é apresentado na Tabela 1.

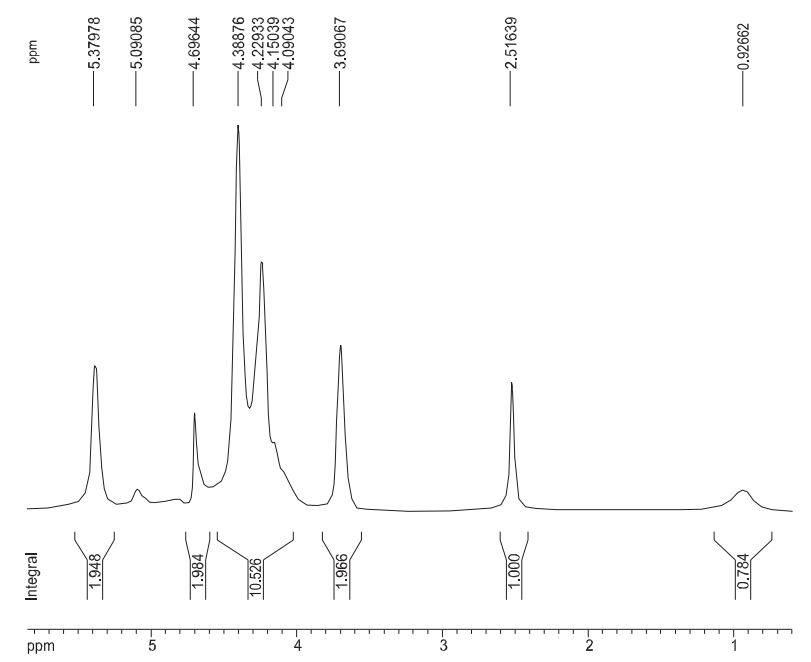

Figura 3. $\mathrm{RMN}^{1} \mathrm{H}$ da quitosana Sigma solubilizada em $1 \mathrm{~mL}$ de solução de $\mathrm{HCl}$ $\mathrm{D}_{2} \mathrm{O}(\mathrm{v} / \mathrm{v})$ por $24 \mathrm{~h}$, inserida em tubo de $5 \mathrm{~mm}$ de diâmetro e analisada a $60^{\circ} \mathrm{C}$

A diferença nos graus médios de desacetilação obtida empregando-se as duas técnicas pode ser devida à maior sensibilidade da técnica de ressonância magnética nuclear, que é uma técnica precisa para determinação de compostos orgânicos, enquanto a técnica condutométrica é menos precisa e pode possuir muitos interferentes. No entanto, esses resultados são concordantes com aqueles normalmente encontrados neste tipo de estudo ${ }^{31}$. A quitosana Aldrich foi selecionada por apresentar um maior grau médio de desacetilação.

\section{Remoção de íons metálicos de efluentes}

Foi estudada inicialmente a co-precipitaçao dos cátions metáli$\cos \mathrm{Cu}^{2+}, \mathrm{Pb}^{2+}, \mathrm{Cd}^{2+}, \mathrm{Cr}^{3+}, \mathrm{Hg}^{2+}$ empregando-se a quitosana dissolvi- da em $\mathrm{HCl}$ 0,05 $\mathrm{mol} \mathrm{L}^{-1}$. Para esse estudo foram preparadas soluções desses cátions metálicos em concentrações variando de 0,55 a 2160 $\mathrm{mg} \mathrm{L}^{-1}\left(5 \times 10^{-5}\right.$ a $\left.0,10 \mathrm{~mol} \mathrm{~L}^{-1}\right)$. Alíquotas de $3,0 \mathrm{~mL}$ das soluções de diferentes íons metálicos foram adicionadas, separadamente, na solução contendo $0,200 \mathrm{~g}$ de quitosana Aldrich dissolvida em $40 \mathrm{~mL}$ de solução de $\mathrm{HCl} 0,05 \mathrm{~mol} \mathrm{~L}^{-1}$, sendo então agitadas a $100 \mathrm{rpm}$ por 3 h. Para a co-precipitação das espécies metálicas com o biopolímero e o hidróxido de sódio, foram adicionadas alíquotas variando de 10 a $14 \mathrm{~mL}$ de $\mathrm{NaOH} 0,17 \mathrm{~mol} \mathrm{~L}^{-1}$ às soluções daqueles cátions metálicos, com o auxílio de uma bureta, mantendo a solução sob agitação constante até o pH final atingir 8,5-9,5. Experimentos paralelos nas mesmas condições experimentais foram feitos na ausência de solução de quitosana, objetivando avaliar o efeito desse biopolímero na co-precipitação destas espécies metálicas.

Após um período mínimo de $30 \mathrm{~min}$, necessário para a total decantação dos precipitados, estes foram filtrados e as concentrações desses cátions metálicos, nos respectivos filtrados, foram determinadas empregando-se espectrofotometria de absorção atômica e no caso do mercúrio, por ICP-OES e espectrofotometria no $\mathrm{UV}^{35}$. A Tabela 2 apresenta alguns dos resultados obtidos no estudo da remoção de cátions metálicos das soluções, empregando-se o método proposto e aquele empregando apenas a precipitação com solução de hidróxido de sódio $0,17 \mathrm{~mol} \mathrm{~L}^{-1}$. Nesta tabela, na primeira coluna são apresentadas as espécies metálicas estudadas; na segunda coluna, a concentração inicial; na terceira, a concentração final dos íons metálicos no filtrado, após tratamento empregando o método proposto, seguido da concentração das espécies, após o tratamento com solução de $\mathrm{NaOH}$ e, finalmente, os limites estabelecidos pelo CONAMA (mg L $\left.\mathrm{L}^{-1}\right)$.

O íon metálico liga-se ao nitrogênio do agrupamento amino em meio ácido, onde há substituição do hidrogênio pelo íon metálico, como observado na Figura 4.
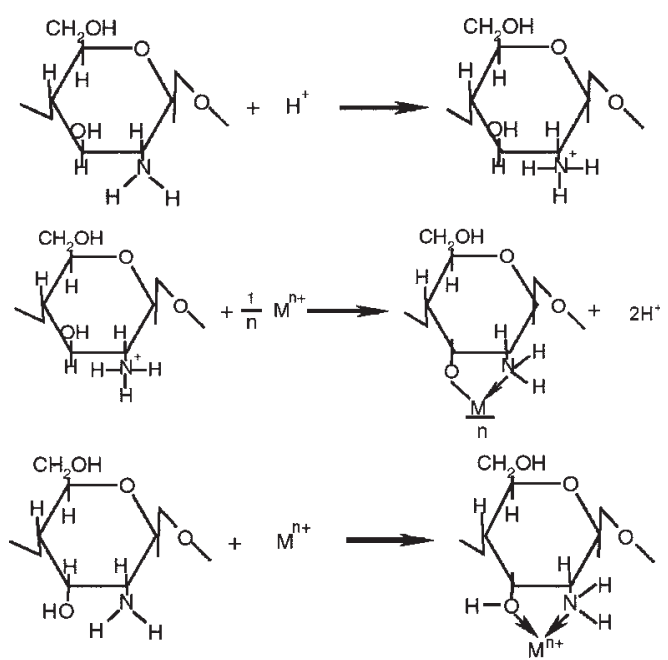

Figura 4. Mecanismo de interação dos íons metálicos com a quitosana, de acordo com o método proposto

O método proposto apresenta maior eficiência de remoção de íons metálicos em comparação aos outros métodos estudados neste trabalho. O aumento da eficiência de remoção é devido ao aumento do grau de complexação do íon metálico pelos grupos amino e hidroxila da quitosana em $\mathrm{pH}$ acima de $6^{22,23}$ e também co-precipitação dos hidróxidos ou óxidos dos íons metálicos. Após separação do precipitado, o sobrenadante pode ser descartado após ajuste do pH entre 6,0 e 7,0 com solução de ácido clorídrico.

Como pode ser observado, o método proposto apresentou maior eficiência na remoção dos íons metálicos, sendo que as concentrações 
Tabela 2. Comparação da remoção dos íons metálicos em solução com a quitosana Aldrich, utilizando o método proposto e a precipitação com $\mathrm{NaOH}$

\begin{tabular}{lcccc}
\hline Espécie metálica & $\begin{array}{c}\text { Concentração inicial } \\
\text { dos íons }\left(\mathrm{mg} \mathrm{L}^{-1}\right)\end{array}$ & $\begin{array}{c}\text { Concentração final dos } \\
\text { íns utilizando o método } \\
\text { proposto }\left(\mathrm{mg} \mathrm{L}^{-1}\right)\end{array}$ & $\begin{array}{c}\text { Concentração final dos íons } \\
\text { após precipitação com } \\
\mathrm{NaOH}\left(\mathrm{mg} \mathrm{L}^{-1}\right)\end{array}$ & $\begin{array}{c}\text { Limite } \\
\text { CONAMA } \\
\left(\mathrm{mg} \mathrm{L}^{-1}\right)\end{array}$ \\
\hline $\mathrm{Cu}(\mathrm{II})$ & $<\mathrm{LD}^{*}$ & $0,26 \pm 0,01$ & 0,5 \\
$\mathrm{~Pb}(\mathrm{II})$ & $<\mathrm{LD} * *$ & $2,7 \pm 0,1$ & 0,05 \\
$\mathrm{Cd}(\mathrm{II})$ & 183,7 & $0,09 \pm 0,01$ & $2,6 \pm 0,5$ & 0,01 \\
$\mathrm{Cr}(\mathrm{III})$ & 215,0 & $<\mathrm{LD}^{* * *}$ & $5,5 \pm 0,5$ & 0,5 \\
$\mathrm{Hg}(\mathrm{II})$ & 109,3 & $<\mathrm{LD} * * *$ & $1,4 \pm 0,5$ & 0,002 \\
\hline
\end{tabular}

*LD= limite de detecção da técnica $\left(2,0 \times 10^{-3} \mathrm{mg} \mathrm{L}^{-1}\right) ; * * \mathrm{LD}=$ limite de detecção da técnica $\left(1,0 \times 10^{-5} \mathrm{mg} \mathrm{L}^{-1}\right)$; *** $\mathrm{LD}=$ limite de detecção da técnica $\left(6,0 \times 10^{-3} \mathrm{mg} \mathrm{L}^{-1}\right)$; **** $\mathrm{LD}=$ limite de detecção da técnica $\left(1,4 \times 10^{-2} \mathrm{mg} \mathrm{L}^{-1}\right)$

das espécies metálicas remanescentes - $\mathrm{Cu}$ (II), $\mathrm{Pb}$ (II) e $\mathrm{Cr}(\mathrm{III})$ - em cada sobrenadante ficaram abaixo dos limites estabelecido pelo CONAMA.

A precipitação promovida empregando solução hidróxido de sódio mostrou-se eficiente apenas para a remoção de $\mathrm{Cu}(\mathrm{II})$ do efluente, sendo que para as demais espécies metálicas a concentração final das espécies ficou acima dos limites estabelecidos pelo CONAMA.

Empregando-se o método proposto para tratamento de efluentes contendo $\mathrm{Pb}(\mathrm{II})$, a concentração dessa espécie metálica no filtrado ficou abaixo do limite estabelecido pelo CONAMA, sendo que o método utilizando apenas hidróxido de sódio como agente precipitante não foi satisfatório para altas concentrações iniciais desse cátion (>180,0 $\left.\mathrm{mg} \mathrm{L}^{-1}\right)$.

$\mathrm{O}$ método proposto apresentou boa eficiência para remoção de íons Cd(II) em concentrações menores que $65,0 \mathrm{mg} \mathrm{L}^{-1}$ (não mostrado na tabela), uma vez que a concentração de Cd(II) no filtrado foi da ordem de $5,0 \times 10^{-3} \mathrm{mg} \mathrm{L}^{-1}$. Por outro lado, como mostrado na Tabela 2, para uma concentração inicial de $215,0 \mathrm{mg} \mathrm{L}^{-1}$ desse cátion metálico, após o tratamento empregando o procedimento proposto, a concentração do filtrado foi $0,09 \pm 0,01 \mathrm{mg} \mathrm{L}^{-1}$, enquanto que foi igual a 2,6 $\pm 0,5 \mathrm{mg} \mathrm{L}^{-1}$ quando se empregou o procedimento com solução de hidróxido de sódio na ausência de quitosana.

Para efluente contendo íons $\mathrm{Cr}$ (III) em concentração inicial de $109,3 \mathrm{mg} \mathrm{L}^{-1}$, após o tratamento empregando-se o método proposto e aquele com precipitação com $\mathrm{NaOH}$, foram obtidas concentrações do filtrado menores que o $\mathrm{LD}$ e de $5,5 \pm 0,5 \mathrm{mg} \mathrm{L}^{-1}$, respectivamente.

Finalmente, o método proposto apresentou boa eficiência de remoção de $\mathrm{Hg}(\mathrm{II})$, sendo que a concentração dessa espécie no filtrado ficou abaixo do limite de detecção do método analítico empregado neste trabalho.

\section{Remoção dos íons metálicos empregando-se colunas empacotadas com quitosana}

O método utilizando a coluna empacotada com quitosana apresentou bons resultados, com remoção de aproximadamente 100\% dos íons metálicos. Porém, há necessidade de maior quantidade de quitosana e maior tempo para remoção dos íons cobre(II), uma vez que a vazão média da solução percolada pela coluna variou de 0,5

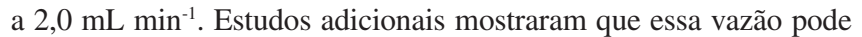
ser aumentada para 5,0 mL min ${ }^{-1}$ sem prejuízo do grau de retenção do íon $\mathrm{Cu}^{2+}$ ou dos demais cátions metálicos estudados.

No estudo da remoção de $\mathrm{Cu}^{2+}$, a massa de quitosana na coluna foi saturada pela percolação de $450 \mathrm{~mL}$ de solução de $\mathrm{Cu}^{2+} 0,01 \mathrm{~mol} \mathrm{~L}^{-1}$, ou seja $0,11 \mathrm{~g}$ de cobre(II)/g quitosana, como pode ser observado na Figura 5. Volumes maiores adicionados de solução de $\mathrm{Cu}^{2+}$ levaram a um aumento crescente da concentração de $\mathrm{Cu}^{2+}$ na solução percolada,

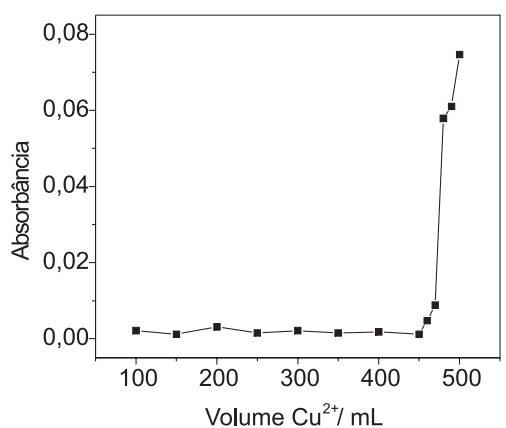

Figura 5. Extração de $\mathrm{Cu}^{2+} 10^{-2} \mathrm{~mol} \mathrm{~L}^{-1}$ em coluna contendo $2,5 \mathrm{~g}$ de quitosana

como pode ser observado nessa figura, indicando assim que os sítios ativos da quitosana foram saturados.

No estudo da remoção do $\mathrm{Pb}^{2+}$, foram adicionadas à coluna empacotada com 2,5 g de quitosana alíquotas de $25 \mathrm{~mL}$ da solução de $\mathrm{Pb}^{2+} 0,1 \mathrm{~mol} \mathrm{~L}{ }^{-1}$, removendo então $0,62 \mathrm{~g}$ de íons $\mathrm{Pb}$ (II)/g de quitosana, como mostra a Figura 6.

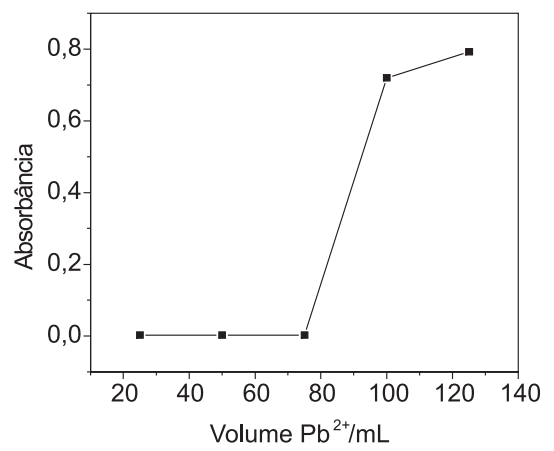

Figura 6. Extração de $\mathrm{Pb}^{2+} 10^{-1} \mathrm{~mol} \mathrm{~L}^{-1}$ em coluna contendo $2,5 \mathrm{~g}$ de quitosana

No estudo do $\mathrm{Cd}^{2+}$, foram adicionadas à coluna empacotada com 2,5 g de quitosana, alíquotas de $25 \mathrm{~mL}(\mathrm{~V}$ total=300 mL) da solução de $\mathrm{Cd}^{2+} 0,001 \mathrm{~mol} \mathrm{~L}^{-1}$, observando-se uma remoção de $1,4 \times 10^{-3} \mathrm{~g}$ de $\mathrm{Cd}(\mathrm{II}) / \mathrm{g}$ de quitosana.

No caso do $\mathrm{Cr}^{3+}$, foram adicionadas à coluna empacotada, com 2,5 g quitosana, alíquotas de $25 \mathrm{~mL}$ (V total=100 mL) da solução de $\mathrm{Cr}^{3+} 0,001 \mathrm{~mol} \mathrm{~L}^{-1}$. Após a percolação do cátion retido na coluna, a remoção desse cátion metálico foi de $2,6 \times 10^{-3} \mathrm{~g}$ de crômio(III)/ $\mathrm{g}$ de quitosana.

Finalmente, no estudo da remoção de $\mathrm{Hg}^{2+}$ das soluções, adicionaram-se à coluna empacotada com 2,5 g quitosana, alíquotas de $25 \mathrm{~mL}$ (V total=450 mL) da solução de $\mathrm{Hg}^{2+} 0,001 \mathrm{~mol} \mathrm{~L}^{-1}$. A remoção de mercúrio(II) foi de $1,6 \times 10^{-4} \mathrm{~g}$ de $\mathrm{Hg}$ (II)/g de quitosana. 
Dados na literatura mostram que a quitosana pode apresentar uma ordem de seletividade ou preferência para a adsorção de diferentes cátions metálicos, dependendo do método empregado, da valência do cátion metálico e concentração do extrator ${ }^{22}$.

Como pode ser observado, a coluna contendo quitosana empacotada apresentou eficiência na remoção dos cátions metálicos. Esse estudo foi realizado para comparação com a metodologia proposta. No entanto, comparando-se a massa de quitosana empregada nas colunas e aquela empregada na co-precipitação daqueles íons metálicos, verifica-se que mesmo empregando massas superiores de quitosana nas colunas, os rendimentos de extração foram bem inferiores que aqueles obtidos empregando-se a co-precipitação das espécies metálicas (Tabela 2). No trabalho desenvolvido não se estudou a seletividade da quitosana por aquelas espécies metálicas. Nestes estudos de seletividade, é importante trabalhar com as mesmas concentrações iniciais das espécies metálicas, mesma concentração de quitosana, tempo e temperatura controlados.

\section{CONCLUSÕES}

A quitosana previamente solubilizada em meio ácido e, posteriormente precipitada com o cátion metálico, em meio básico foi mais eficiente na remoção dos cátions metálicos estudados nesse trabalho, tendo rendimento superior à quitosana sólida empacotada em coluna ou precipitação com solução de hidróxido de sódio.

$\mathrm{O}$ método proposto foi eficaz para remoção dos íons $\mathrm{Cu}^{2+}, \mathrm{Cr}^{3+}$, $\mathrm{Pb}^{2+}, \mathrm{Cd}^{2+}$ e $\mathrm{Hg}^{2+}$ em solução, sendo que as concentrações remanescentes desses cátions ficaram abaixo dos LDs da técnica analítica empregada, que são menores ou próximas àquelas concentrações estabelecidas pelo CONAMA. Além disso, após solubilização da quitosana, a precipitação das espécies metálicas com a quitosana em meio básico foi realizada em $30 \mathrm{~min}$, muito mais rápida que a remoção dos íons empregando a quitosana em coluna, com duração variando de 2 a $8 \mathrm{~h}$. Outrossim, para algumas espécies metálicas, foi possível promover a co-precipitação em tempos da ordem de 10-15 min, sem prejudicar a percentagem de remoção da espécie metálica.

\section{AGRADECIMENTOS}

Aos recursos finaceiros recebidos do CNPq, da CAPES e FAPESP, às bolsas de iniciação científica de B. C. Lourenção (MEC-SESU) e de B. C. Janegitz (FAPESP) e aos Profs. A. G. Ferreira e J. de A. Nóbrega pelo auxílio e discussão das análises das amostras.

\section{REFERÊNCIAS}

1. Sanseverino, A. M.; Ciência Hoje 2002, 31, 21.

2. Lancaster, M.; Green Chemistry: An Introductory Text, Royal Society of Chemistry: Cambridge, 2002.

3. Bailey, S. E.; Olin, T. J.; Bricka, R. M.; Adrian, D. D. A.; J. Hazard. Mater. 1999, 97, 2469
4. http://www.mma.gov.br/port/conama, acessada em Outubro 2005.

5. de Azevedo, F. A.; Chasin, M. A. A. da; Metais: Gerenciamento da Toxicidade, Atheneu: São Paulo, 2003.

6. Babel, S.; Kurniawan, T. A.; J. Hazard. Mater. 2003, 97, 219.

7. Basílio, M. S.; Friese, K.; de Lena, J. C.; Nalini Jr., H. A.; Roeser H. M. P.; Quim. Nova 2005, 28, 822.

8. Prado, A. G. S.; Faria, E. A.; Padilha, P. M.; Quim. Nova 2005, 28, 544.

9. Pergher, S. B. C.; Coavilla, M.; Detoni, C.; Machado, N. R. C. F.; Quim Nova 2005, 28, 397.

10. Petroni, S. L. G.; Pires, M. A. F.; Munita, C. S.; Quim Nova 2000, 23, 477.

11. Kurita, K.; Mar. Biotechnol. 2006, 8, 203.

12. Shi, C. M.; Zhu, Y.; Ran, X. Z.; Wang, M.; Su, Y. P.; Cheng, T. M.; J. Surgical Res. 2006, 133, 185

13. El-Sawy, S. M.; Abu-Ayana, Y. M.; Abdel-Mohdy, F. A.; Anti-Corrosion Methods and Materials 2001, 48, 227.

14. Cardenas, G.; Orlando, P.; Edelio, T.; Int. J. Biol. Macromol. 2001, 28, 167.

15. Shi, C.; Zhu, Y.; Ran, X.; Wang, M.; Su, Y.; Cheng, T.; J. Surgical Res. 2006, 133,185 .

16. Bautista-Baños, S.; Hernández-Lauzardo, A. N.; Velázquez-del Valle, M. G.; Hernández-Lopez, M.; Barka, E. A.; Bosquez-Molina, E.; Wilson, C. L.; Crop Protection 2006, 25, 108.

17. Magnin, D.; Lefebvre, J.; Chornet, E.; Dumitriu, S.; Carbohydr. Polym. 2004, 55, 437.

18. Rodas, A. C. D.; Ohnuki, T.; Mathor, M. B.; Lugao, A. B.; Nucl. Instrum. Methods Phys. Res., Sect. B 2005, 236, 536.

19. Coutinho, P.; Rema, P.; Otero, A.; Pereira, O.; Fábregas, J.; Aquaculture Res., 2006, 37, 793.

20. Crini, G.; Bioresour. Technol. 2006, 97, 1061.

21. Vieira, R. S.; Beppu, M. M.; Water Res. 2006, 40, 1726.

22. Varma, A. J.; Deshpande, S. V.; Kennedy, J. F.; Carbohydr. Polym. 2004, $55,77$.

23. Guibal, E.; Sep. Purif. Technol. 2003, 38, 43.

24. Canella, K. M.; Carvalho, N.; Balaban, R.; Quim. Nova 2001, 24, 13.

25. Khor, E.; Curr. Opin. Solid State and Materials Science 2002, 6, 313.

26. Zwirtes, I. R. W.; Vieira, I.C.; Quim. Nova 2006, 29, 923.

27. Wan Ngah, W. S.; Endud, C. S.; Mayanar, R.; Reative \& Polymers 2002, 50,181

28. Silva, H. S. R. C.; dos Santos, K. S. C. R.; Ferreira, E. I.; Quim. Nova 2006, 29, 776.

29. Klug, M.; Sanches, M. N. M.; Laranjeira, M. C. M.; Fávere, V. T.; Rodrigues, C. A.; Quim. Nova 1998, 21, 410.

30. Geremias, R.; Pedrosa, R. C.; Benassi, J. C.; Favere, V.T.; Stolberg, J.; Menezes, C. T. B.; Laranjeira, M. C. M.; Environ. Technol. 2003, 24, 1509.

31. Dockal, E. R.; Cavalheiro, E. T. G.; dos Santos, J. E.; Soares, J. da P.; Campana Filho, S. P.; Polímeros: Ciência e Tecnologia 2003, 13, 242.

32. Signini, R.; Campana Filho, S. P.; Polímeros: Ciência e Tecnologia 1998, 4,63 .

33. Janegitz, B. C.; Lourenção, B. C.; Lupetti, K. O.; da Silva, C.; FatibelloFilho, O.; Resumos da XIV SBQ-Regional, São Carlos, Brasil, 2003.

34. Lupetti, K. O.; Fagury, R. L. R. P.; da Silva, C.; Leite, O. D.; FatibelloFilho, O.; Resumos do $12^{\circ}$ Encontro Nacional de Química Analítica, São Luís, Brasil, 2003.

35. Park, S. M.; Choi, H. S.; Anal. Chim. Acta 2002, 459, 75.

36. Sashiwa, H.; Saimoto, H.; Shigemasa, Y.; Tokura, S.; Carbohydr. Res. 1993, 242, 167.

37. Fernandez-Megia, E.; Novoa-Carballal, R.; Quinoa, E.; Riguera, R.; Carbohydr. Polym. 2005, 61, 155.

38. Brugnerotto, J.; Desbrieres, J.; Roberts, G.; Rinaudo, M.; Polymer 2001, $42,9921$.

39. Sridhar, S.; Susheela, G.; Reddy, G.; Khan, A.; Polym. Int. 2001, 50, 1156.

40. Zhang, Y.; Xue, C.; Xue, Y.; Gao, R.; Zhang, X.; Carbohydr. Res. 2005, 340, 1914. 